\title{
Rates of morphological evolution, asymmetry and morphological integration of shell shape in scallops
}

\author{
Emma Sherratt ${ }^{1,2^{*}}$ (D), Jeanne M. Serb ${ }^{2}$ and Dean C. Adams ${ }^{2,3}$
}

\begin{abstract}
Background: Rates of morphological evolution vary across different taxonomic groups, and this has been proposed as one of the main drivers for the great diversity of organisms on Earth. Of the extrinsic factors pertaining to this variation, ecological hypotheses feature prominently in observed differences in phenotypic evolutionary rates across lineages. But complex organisms are inherently modular, comprising distinct body parts that can be differentially affected by external selective pressures. Thus, the evolution of trait covariation and integration in modular systems may also play a prominent role in shaping patterns of phenotypic diversity. Here we investigate the role ecological diversity plays in morphological integration, and the tempo of shell shape evolution and of directional asymmetry in bivalved scallops.

Results: Overall, the shape of both valves and the magnitude of asymmetry of the whole shell (difference in shape between valves) are traits that are evolving fast in ecomorphs under strong selective pressures (gliders, recessers and nestling), compared to low rates observed in other ecomorphs (byssal-attaching, free-living and cementing). Given that different parts of an organism can be under different selective pressures from the environment, we also examined the degree of evolutionary integration between the valves as it relates to ecological shifts. We find that evolutionary morphological integration is consistent and surprisingly high across species, indicating that while the left and right valves of a scallop shell are diversifying in accordance with ecomorphology, they are doing so in a concerted fashion.

Conclusions: Our study on scallops adds another strong piece of evidence that ecological shifts play an important role in the tempo and mode of morphological evolution. Strong selective pressures from the environment, inferred from the repeated evolution of distinct ecomorphs, have influenced the rate of morphological evolution in valve shape and the magnitude of asymmetry between valves. Our observation that morphological integration of the valves making up the shell is consistently strong suggests tight developmental pathways are responsible for the concerted evolution of these structures while environmental pressures are driving whole shell shape. Finally, our study shows that directional asymmetry in shell shape among species is an important aspect of scallop macroevolution.
\end{abstract}

Keywords: Geometric morphometrics, Bivalve, Mollusc, Pectinidae, Morphological integration, Tempo and mode

\footnotetext{
* Correspondence: emma.sherratt@gmail.com

${ }^{1}$ Department of Genetics and Evolution, School of Biological Sciences, The

University of Adelaide, Adelaide, South Australia 5005, Australia

${ }^{2}$ Department of Ecology, Evolution, and Organismal Biology, lowa State

University, Ames, IA 50011, USA

Full list of author information is available at the end of the article
}

\section{Ciomed Central}

(c) The Author(s). 2017 Open Access This article is distributed under the terms of the Creative Commons Attribution 4.0 International License (http://creativecommons.org/licenses/by/4.0/), which permits unrestricted use, distribution, and reproduction in any medium, provided you give appropriate credit to the original author(s) and the source, provide a link to the Creative Commons license, and indicate if changes were made. The Creative Commons Public Domain Dedication waiver (http://creativecommons.org/publicdomain/zero/1.0/) applies to the data made available in this article, unless otherwise stated. 


\section{Background}

It has long been observed that rates of morphological evolution vary across different taxonomic groups [1-3] and variation in rates of evolution has been proposed as one of the main drivers for the great diversity of organisms on Earth (e.g., [4]). A central aim in evolutionary biology is therefore to document the observed variability in the tempo of evolution in groups of closely related species and identify extrinsic and intrinsic factors pertaining to this variability. Fortunately, this is now possible because of the accumulation of large quantitative phenotypic datasets and advances in phylogenetic comparative methods [5-14]. Historically, variability in the tempo of morphological diversification across clades has been investigated with respect to phyletic factors such as lineage diversification, species richness or clade age [15-19]. While these are likely correlates, aspects of an organism's biology, ecology and development are arguably the underlying factors driving evolutionary changes in morphology.

Ecological hypotheses feature prominently in observed differences in phenotypic evolutionary rates across lineages. Transitioning from one ecological niche to another can promote changes in the tempo of morphological evolution by either limiting morphological diversification or substantially accumulating change (e.g., [20, 21-24]). For example, rock-dwelling and arboreal lizard species display reduced rates of morphological evolution compared to their terrestrial counterparts [22], while coral reef habit is correlated with increased rates of phenotypic evolution in fish $[20,23]$. Indeed, ecological opportunity is a primary factor implicated in regulating the tempo of morphological diversification in adaptive radiations [25-28]. In a similar manner, elevated rates of phenotypic change are typically found in organisms occupying disturbed or novel environments (e.g., [29]) or facing high predation pressures [30, 31]. Together these studies demonstrate that the habitat use and an organism's environment affect the rate at which morphological diversity accumulates.

In some cases, external selection pressures can act differentially on separate traits of the same individual, resulting in variability in the rates of phenotypic evolution within organisms (e.g., [12, 32, 33-36]). For example, traits under sexual selection versus those under natural selection experience distinct selective regimes, which can result in different rates of evolutionary changes among traits [32]. Furthermore, traits that are under strong selective pressures resulting from biomechanical constraints [36], or those that perform several functions and face tradeoffs [37], may exhibit lower rates of morphological evolution than other traits not involved in such behaviours $[36,37]$. Under such circumstances, differential selection across traits may cause an evolutionary decoupling, where some sets of traits covary tightly with one another but are relatively independent from other sets of traits. When viewed across a phylogeny, this pattern is known as evolutionary morphological integration [38]. Integration is expected to decrease when each trait is under different, possibly antagonistic, selection pressures [39], such as in the evolutionary decoupling of mammalian fore- and hind-limbs as a result of life history changes [40] or different locomotory behaviour [41]. These examples also demonstrate how an animal's ecology influences evolutionary morphological integration. Therefore, integration and the tempo of morphological change are expected to be tightly linked in macroevolution, and explicitly examining the degree of integration between different traits is necessary when estimating the tempo of morphological evolution of sets of traits $[13,36,42]$.

Morphological evolution of bivalved scallops (Pectinidae) is strongly influenced by ecological niche shifts [43-46], and thus they present an attractive system with which to study the role ecological diversity on the dynamics of phenotypic evolution. Scallops exhibit substantial diversity of shell morphologies related to the ecology ("life habit" sensu [47]) of the animal: adult scallops can be broadly organised into six ecomorphs that vary in their level of mobility (cementing, nestling, byssal-attaching, recessing, free-living, and gliding (longdistance swimming): [44, 47]). Further, the mode of shell shape evolution in scallops differs among ecomorphs. For example, recessing scallops, those that bury themselves under sand, have evolved by directional evolution resulting in the most derived species displaying the most pronounced concave left valve shape [45]. Gliding scallops, those with high-performance swimming ability (described in [48]), have convergently evolved a disc-like, flattened valve shape [43, 46]; while byssal-attaching and free-living scallops are morphologically similar within ecomorph but display substantial evolutionary plasticity [45]. Given these different modes of evolution, it is likely that the tempo of morphological evolution may differ among ecomorphs as well, but to date this hypothesis has yet to be examined.

The scallops are also an attractive system with which to examine evolutionary morphological integration. The bivalve shell is a simple modular system comprised of two valves attached with a hinge on the dorsal side. This two-valved arrangement poses an interesting challenge to studying morphological evolution, as bivalved animals can have both object symmetry (anterior-posterior symmetry within a valve) as well as matching symmetry (degree of similarity in shape and size between the left and right valves) [49]. Note that object symmetry, relating to the anterior-posterior axis along a single valve, is not considered here, and thus asymmetry discussed herein refers to matching symmetry of valves. Most bivalves are orientated such that the hinge is perpendicular to the surface of a substrate. Because the two valves experience 
similar environmental conditions, there is a strong expectation of symmetry between the left and right valves $[47,50]$. However, scallops are unlike most bivalves as they live on the surface of a substrate (epifaunal) with the right valve (lower valve) usually in contact with the substrate, while the left valve (upper valve) is more often exposed ([51], but see [52]). This orientation predicts that the two valves will experience different selective pressures resulting in asymmetry between the two valves (discussed in [47]). Here we refer to this as directional asymmetry (DA), the consistent difference between a pair of morphological structures [53, 54]. Importantly, DA in scallops has never been quantified at a macroevolutionary scale, and the degree to which the two valves are evolving in concert (morphological integration) has yet to be tested.

Here we investigate the role ecological diversity plays in morphological integration and tempo of shell shape evolution and directional asymmetry in scallops. We estimate the magnitude of morphological integration in scallop shell shape across species, and examine how the strength varies among ecomorphs to understand how the complex shell is evolving in response to changing ecological demands. Then we estimate the tempo of evolution in three traits: the left valve shape; the right valve shape; and the difference in shape between valves (amount of asymmetry), which is a trait representing the whole shell. With these estimates, we test whether the tempo of morphological change differs among ecomorphs, and whether there are within-shell differences in rates (comparing left versus right valves). We predict substantial differences of morphological integration and tempo among ecomorphs because of the differing functional constraints imposed by the life habit, the degree of exposure each valve contends with, and the different roles of the left and right valves. Further, we expect particularly high rates of morphological change and stronger integration in gliding and recessing species because these ecomorphs have been previously identified to be under strong natural selection [43-46]. We characterise shell shape (left and right valves) with geometric morphometrics for 86 species across the six ecomorphs, and for the remainder of the paper, we follow the malacological literature and use the terms 'equivalve' (similar) and 'inequivalve' (dissimilar) to describe the degree of asymmetry between the left and right valves [55]. Shape data are analysed in a phylogenetic framework using recent statistical advances for multidimensional traits that permits morphological integration to be examined in an evolutionary context [56] and net phenotypic evolutionary rates to be calculated between traits of the same individuals and between groups of species $[11,13]$. Implications of our findings are discussed in terms of how rates of evolution and the evolution of morphological integration, impact macroevolutionary trends of phenotypic diversity.

\section{Methods}

\section{Samples and morphometric analyses}

We sampled shells from 1081 adult individuals for 123 species and spanning the range of ecomorphs (museum collections listed in Additional file 1: Table S1 and Acknowledgments). However, because not all shells are preserved with both valves intact, nor are all species included in the most current molecular phylogenetic hypothesis [45], the total number of shells available to study was 669 individuals from 86 species (2 cementing, 1 nestling, 48 byssal-attaching, 11 recessing, 18 free-living, and 6 gliding species). These proportions of ecomorph categories in our taxonomic sample are similar to their representation across extant species the family (in square brackets): cementing $=2 \%[1.9 \%]$; nestling $=1 \%[0.75 \%]$; byssal-attaching $=57 \% \quad[66 \%]$; free-living $=20 \% \quad[16.3 \%]$; recessing $=12 \%[12.1 \%]$; gliding $=6 \%[3 \%]$ [44] .

Landmark data collection follows that of previous studies $[43,45,46]$ and is presented in more detail in Sherratt et al. [45]. In summary, we obtained three-dimensional (3D) surfaces representing the left and right valves using a NextEngine 3D scanner (Next Engine Inc., Santa Monica, CA). Next, valve shape was characterised using landmarkbased geometric morphometrics [57-59]. We used a combination of fixed landmarks representing homologous points and semilandmarks, points on curves and surfaces $[58,60]$. On each 3D surface, we placed 5 landmarks around the auricles and umbo (Fig. 1). Scallop left and right valves have matching symmetry along the line of contact between the closed valves (i.e., commissural plane; [61]), thus the right valves were digitised so that the landmark points are a reflection along the dorsal/ventral axis. Then, 197 equally-spaced landmarks were digitised on the valve surface to characterise the boundary contours of the valve and auricles as well as the valve curvature in the $\mathrm{z}$ dimension. Each valve was measured twice to account for measurement error. The landmark data from the left and right valves were treated as separate structures and were thus aligned separately using a generalised Procrustes superimposition [62], where the semilandmarks were permitted to slide along their tangent directions [60] in order to minimise Procrustes distance between specimens. Morphometric analyses were performed in R v.3.3.1 [63] using the geomorph library v.3.0.4 [64].

\section{Comparative analyses}

Because species are not independent of one another, all statistical analyses evaluating our predictions were conducted using a phylogenetic comparative framework. We used a time-calibrated molecular phylogeny [45] that was pruned to only include the 86 species in this study. To examine morphological integration and characterise the patterns of shape covariation between the left and right valves across all species, we used two-block partial least 

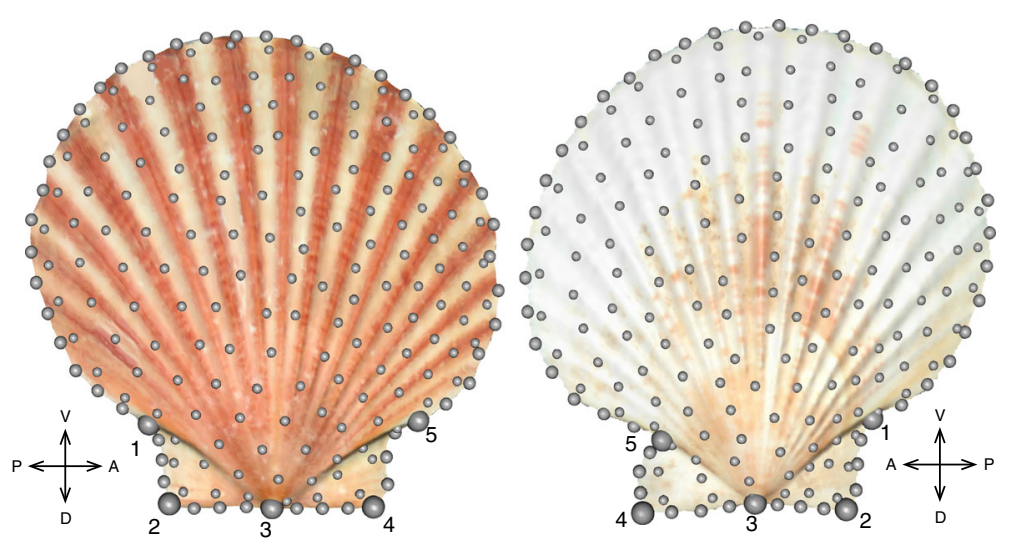

Fig. 1 Three-dimensional surface scans of the left and right valves of a representative scallop, with the landmarks and semilandmarks shown. Five landmarks are numbered and represented by large dots and the semilandmarks are shown as small dots. Landmark 1: ventro-posterior auricle, 2: dorsoposterior auricle, 3: umbo, 4: dorsoanterior auricle, 5: ventroanterior auricle. In life, the left valve ('upper') is usually oriented upwards, with the right valve ('lower') against the substrate, hence the visible colour differences shown here

squares (PLS) analysis [65] and evaluated the statistical significance in a phylogenetic context [56]. The strength of covariation between the valves was calculated as the correlation coefficient ( $r$ pLS) of the first PLS axis of each valve. The $r_{\text {PLS }}$ was calculated for all 86 species using species mean shapes, as well as for each ecomorph (excluding the single nestling species). Each test was statically assessed by a permutation procedure (1000 permutations each). To test whether the strength of integration differs between ecomorphs, we compared their effect sizes (Z-scores), which provides a standardised measure of the strength of integration in each dataset for formal quantitative comparisons [66]. To visualise the pattern of morphological integration, we performed a two-block PLS analysis of all 669 specimens and plotted the first PLS axes of the left valve against that of the right. The shape changes along these axes was visualised using a thin-plate spline method to warp a 3D surface mesh of each valve to the mean shape and from there to the minima and maxima of the axes (e.g., $[67,68])$.

The magnitude of asymmetry was estimated as the absolute difference between left and right valve shape, measured as Procrustes distance. To do this, we performed a second Procrustes superimposition of the left and right valves together (where right valves were mirrored along the anterior-posterior axis to match the left valve), again allowing semilandmarks to slide, and calculated the Procrustes distance between left and right valves for all 669 specimens. To test whether the amount of individual asymmetry differed across ecomorphs while accounting for phylogeny, we used a phylogenetic generalised least squares analysis for multidimensional data (PGLS 45, [69]) implemented in geomorph. The significance of the model was evaluated via permutation (1000 iterations).

The tempo of morphological evolution was estimated using the net evolutionary rate parameter under a
Brownian motion model of evolution $\left(\sigma^{2}\right)$ for valve shape among species on the phylogeny. We addressed four hypotheses to examine differences in evolutionary rate between valves and among ecomorphs: 1) the rate of DA evolution will differ among ecomorphs 2) the net rate of valve shape evolution will differ between left and right valves across all species 3 ) the net rate of valve shape evolution will differ among ecomorphs for the a) left valve and b) right valve 4) the rate of evolution will differ between valves within each ecomorph. To do this, we used an approach for multidimensional shape data which obtains estimates of the net evolutionary rate of change in the multidimensional morphospace after phylogenetic transformation [11, 13]. For each hypothesis, evolutionary rates for each ecomorph or trait were obtained, and from them test statistics calculated (a ratio of maximum to minimum evolutionary rates: see Adams 2014b; Denton and Adams 2015). Statistical significance of the observed test measures was then evaluated via phylogenetic simulation, in which tips data were obtained under the null hypothesis of a single Brownian motion process for all species on the phylogeny $[11,13]$. For all evolutionary rate estimations, 95\% confidence intervals were estimated by bootstrapping the individuals used to calculate the species means (1000 iterations). Phylogenetic analyses were performed using the phytools library v.0.5-38 [70], the $A P E$ library v.3.5 [71], and the geomorph library v.3.0.4 [64].

\section{Results}

The overall strength of evolutionary integration between the left and right valve across all species was moderately high $(r$ PLS-all $=0.80, P<0.001)$. When examined by ecomorph, we found the more motile ecomorphs displayed very high levels of integration $\left(r\right.$ PLS-free $=0.95, r_{\text {PLS-glide }}$ 
$=0.94$ ), while species in the sessile ecomorphs exhibited slightly lower levels of integration $(r$ PLS-byssal $=0.88, r$ PLS-recess $=0.88$, all $P<0.05$; cementing and nestling excluded due to sample size). However, the strength of morphological integration ( $\left.r_{\text {pLS }}\right)$ did not differ significantly among these ecomorphs (effect sizes, $Z$ : byssal $=6.5$, recess $=2.6$, free $=4.4$, glide $=1.5, P$-values in Additional file 1 : Table S2), although there was a trend for gliders to be marginally more integrated than the byssal-attaching and freeliving species (both $P=0.06$ ). The pattern of integration between left and right valves among all 669 specimens is shown in Fig. 2. Here, most specimens fell along a single trajectory of shape covariation, indicating concerted evolutionary change in both valves' morphology among species. The shape changes associated with the first PLS axes of each valve (Fig. 2) described similar changes, from a highly convex valve to a flattened valve. The gliding species lied in the region where both valves are very flat, while the byssal-attaching and free-living occupied the region where both valves were convex. The recessing species were a clear exception to this pattern, being offset from the rest - where their right valve was convex and their left valve was flattened.

The magnitude of shell asymmetry was highly variable among species and clearly differed within and between ecomorphs (Fig. 3a, Additional file 1: Figure S1, Table 1A). Recessing species displayed the highest mean asymmetry, as well as the largest variance in asymmetry, while gliding species and free-living species exhibited the lowest mean asymmetry. However, a PGLS of the species' means of asymmetry was not significant between ecomorphs $(F=1.19, P=0.805)$, suggesting that differences in asymmetry were not unexpected when shared evolutionary history was taken into consideration. The rate of DA evolution was quite high for recessing species and gliding species, and low for all other ecomorphs (Fig. 3b), but overall there was no significant difference among ecomorphs $\left(\sigma_{6}^{2}\right.$ habit ratio $\left.=28.2, P=0.573\right)$ despite some significant pairwise differences (Table 1A).

Comparing across all species, the left and right valves differed significantly in overall rates of shape evolution $\left(\sigma_{\mathrm{R} / \mathrm{L}}^{2}\right.$ ratio $\left.=1.17, P<0.001\right)$, with a distinctly lower rate for left valves than for right valves $\left(\sigma_{\text {left }}^{2}=1.72 \times 10^{-7}\right.$, $\sigma_{\text {right }}^{2}=2.01 \times 10^{-7}$ ) (Fig. 4, abscissa). This indicated that the right valve, which is the one usually in contact with the substrate, was more evolutionary labile in its morphology over macroevolutionary time.

Comparing across ecomorphs, the rates for left-valve shape evolution were significantly different (Fig. 4, circles. $\sigma_{6}^{2}$ habit ratio $=2.92, P=0.028$, Table $1 \mathrm{~B}$ ). Recessing species and gliding species showed the highest rates, more than double that of the lowest rates, seen in byssal-attaching and nestling species. Most pairwise rate differences among ecomorphs were not significantly different. Notably, the byssal-attaching species were evolving significantly slower that the recessing, free-living and gliding species.

The right valve displayed a more prominent pattern of variability in evolutionary rates, where there were substantial and significant differences among ecomorphs (Fig. 4, squares. $\sigma_{6}^{2}$ habit ratio $=5.16, P=0.001$, Table $1 C$ ). Here, the nestling species displayed the highest rate, followed jointly by the recessers and gliders, while the byssal and free-living species exhibited the lowest rates of shape evolution. Biologically, this difference in evolutionary rates corresponds to differences in natural

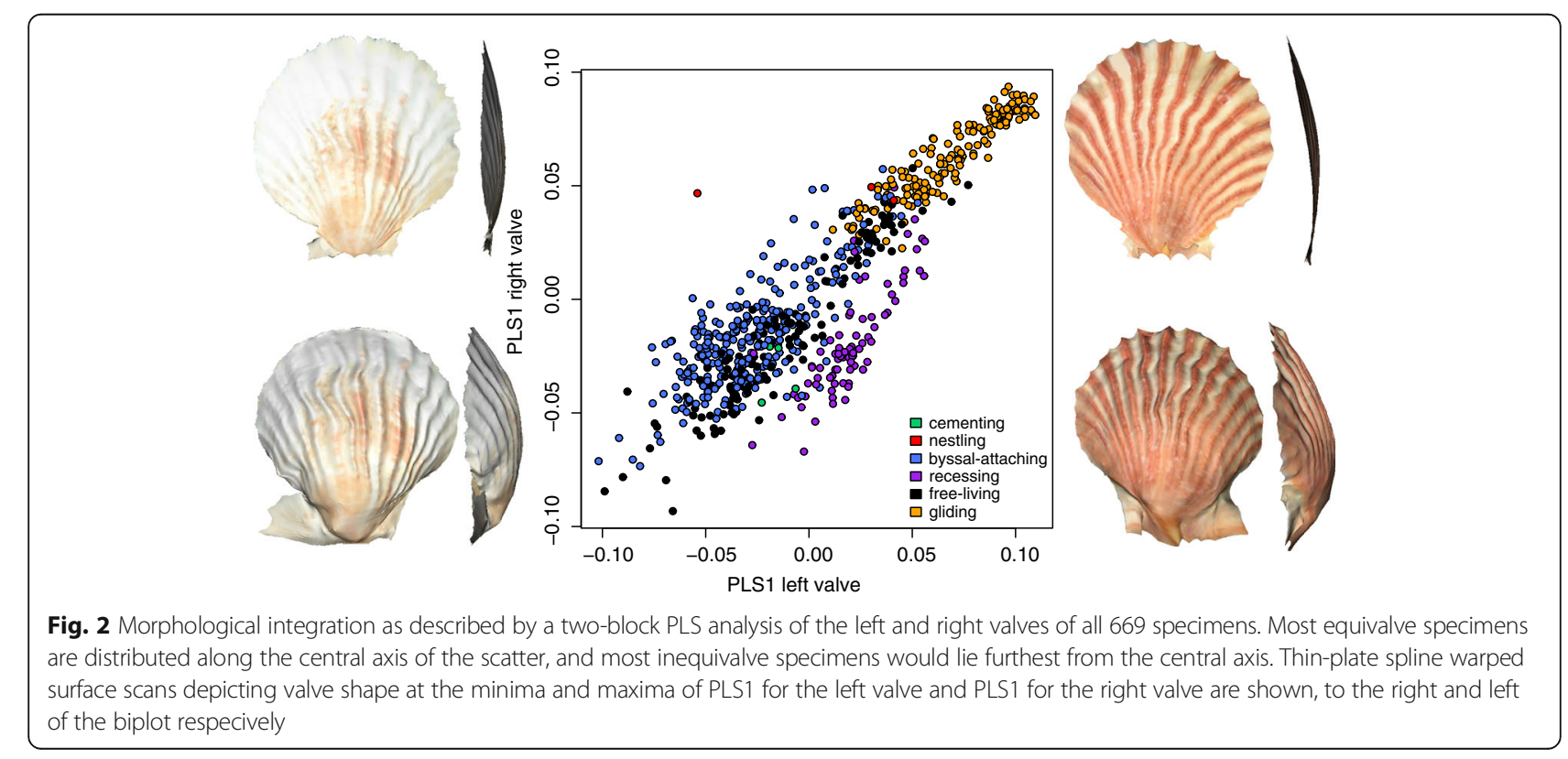




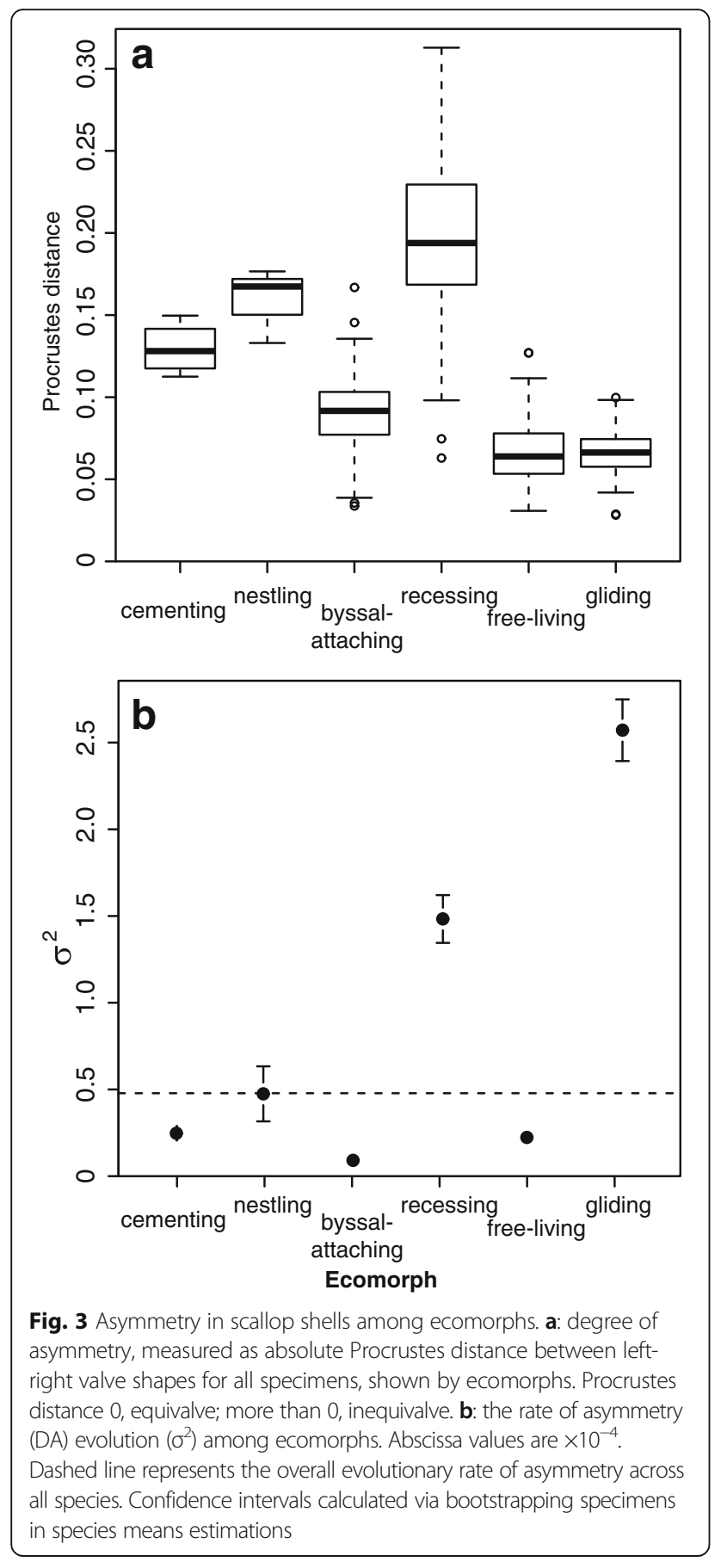

history, as in scallops the right valve is predominantly in contact with the substrate. For instance, in recessing species that excavate and then settle the right valve into a depression in sand, the right valve has evolved to be substantially more convex compared to that of the byssal-attachers. Conversely, the gliding species have evolved a much flatter right valve, relative to those of free-living and byssal-attaching species. The byssal-
Table 1 Pairwise $P$-values for comparisons of morphological rate estimates for degree of asymmetry (A), left valves (B) and right valves (C) among ecomorphs

\begin{tabular}{|c|c|c|c|c|c|}
\hline & cementing & nestling & byssal-attaching & recessing & free-living \\
\hline \multicolumn{6}{|l|}{ A) } \\
\hline nestling & 0.758 & & & & \\
\hline byssal-attaching & 0.744 & 0.631 & & & \\
\hline recessing & 0.717 & 0.877 & 0.006 & & \\
\hline free-living & 0.968 & 0.82 & 0.201 & 0.133 & \\
\hline gliding & 0.201 & 0.532 & 0.002 & 0.914 & 0.037 \\
\hline \multicolumn{6}{|l|}{ B) } \\
\hline nestling & 0.385 & & & & \\
\hline byssal-attaching & 0.327 & 0.787 & & & \\
\hline recessing & 0.036 & 0.004 & 0.001 & & \\
\hline free-living & 0.51 & 0.106 & 0.001 & 0.011 & \\
\hline gliding & 0.1 & 0.017 & 0.001 & 0.573 & 0.092 \\
\hline \multicolumn{6}{|l|}{ C) } \\
\hline nestling & 0.099 & & & & \\
\hline byssal-attaching & 0.009 & 0.001 & & & \\
\hline recessing & 0.141 & 0.431 & 0.001 & & \\
\hline free-living & 0.091 & 0.002 & 0.016 & 0.001 & \\
\hline gliding & 0.284 & 0.332 & 0.001 & 0.706 & 0.001 \\
\hline
\end{tabular}

$P$-values significant at the $5 \%$ level are given in bold. See Fig. $3 b$ and Fig. 4 for corresponding rate estimates

attaching species are evolving significantly slower than all the other life-habits.

Focussing within each ecomorph, the difference in evolutionary rates between left and right valves differed among ecomorphs in terms of statistical significance, but generally, the right valve shape evolved faster than the left (except the free-living ecomorph, Fig. 4). In the single nestling species, Pedum spondyloideum, the rate of evolution in the right valve was almost six times higher than the left $\left(\sigma_{\mathrm{R} / \mathrm{L}}^{2}\right.$ ratio $\left.=5.82\right)$. For the two cementing species, the rate of evolution in the right was higher than the left $\left(\sigma_{\mathrm{R} / \mathrm{L}}^{2}\right.$ ratio $\left.=1.73\right)$. Gliding and recessing species also showed much higher rates of evolution in the right valve (gliding $\sigma_{\mathrm{R} / \mathrm{L}}^{2}$ ratio $=1.96, P=0.031$; recessing $\sigma_{\mathrm{R} / \mathrm{L}}^{2}$ ratio $=1.67, P=0.014)$. In contrast, the left valve of free-living species displayed higher rates than the right valve, but these were not significantly different $\left(\sigma_{\mathrm{R} / \mathrm{L}}^{2}\right.$ ratio $\left.=0.94, P=0.594\right)$. Byssal-attaching species had low rates for both valves and these rates were not significantly different $\left(\sigma_{\mathrm{R} / \mathrm{L} \text { ratio }}^{2}=1.00, P=0.965\right)$.

\section{Discussion}

Bivalved scallops have evolved a diverse array of shell shapes, by a variety of evolutionary modes (i.e., divergence, convergence and directional evolution) in response to macroevolutionary transitions between ecomorphs [43-46]. This study adds to a growing body of literature on 


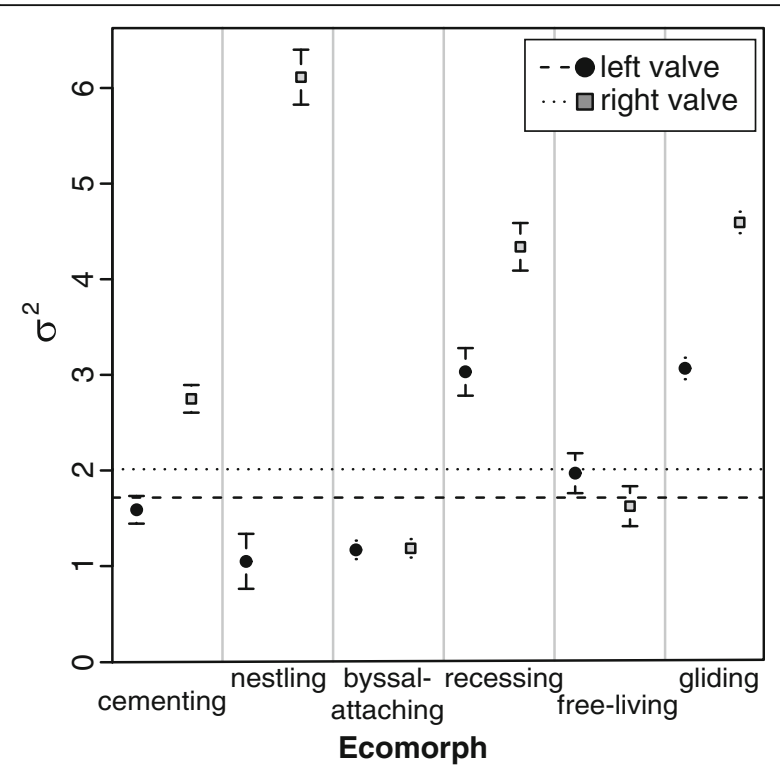

Fig. 4 Phylogenetic evolutionary rate $\left(\sigma^{2}\right)$ of shape evolution among ecomorphs for the left (circle) and right (square) valves, with their 95\% Cls. Abscissa values are $\times 10^{-7}$. Dashed and dotted lines represent the overall evolutionary rate for the left and right valves respectively. Pairwise comparisons between ecomorphs by valve are presented in Table 1 . Confidence intervals were calculated via bootstrapping specimens in species-means estimations

macroevolution of scallops by demonstrating that these ecomorphs also differ substantially in the tempo of shell shape evolution (both valves) and in the magnitude of DA between the left and right valves, but not in the strength of morphological integration.

At the species level, bivalved scallop shells are evolving as an integrated unit. Our results suggest that left and right valves of all sampled species are evolving in concert, displaying moderate to high degrees of shape covariation (integration), whose levels are comparable across ecomorphs. To the best of our knowledge, the strength of morphological integration between valves of scallops, or indeed any other bivalved molluscs, has not been previously examined using geometric morphometric methods to quantify shape covariation. Our study complements the theoretical discussion of phenotypic integration, which has been presented as an important facet of bivalve evolution (e.g. [72, 73, 74]). Morphological integration is a central aspect of macroevolution, because the degree of correlated evolution among structures is expected to influence the evolvability of a clade [75-77]. The two valves of bivalve molluscs are thought to have developed in from a single-valved ancestral condition $[78,79]$ where the shell field elongated dorsoventrally and subsequently folded along the middorsal region [47, 80]. This would suggest that the two valves are closely associated during development and share the same gene regulatory pathways [81]. The strength of covariation between parts of articulated morphological structures would be much lower than what we observed here if the two valves are evolving as separate 'modules', for example in mammalian limbs [40,41] and mantis shrimp claws [82, 83]. We propose that high evolutionary integration in scallop shells across all species is the result of a functional constraint for the hinge elements and shape of the commissural margin between left and right valves to interlock.

Nevertheless, in spite of the strong phenotypic integration found between valves, we found that the differences in the shape between the left and right valves - the magnitude of DA - varied substantially among species of scallops and relates strongly to ecomorph type, and that this variation in asymmetry followed a continuum across the life habits displayed by the various ecomorphs. For example, the gliding species, along with free-living and byssal-attaching species, displayed the lowest levels of asymmetry and thus were the most equivalved in their shell shape, whilst more sedentary taxa found in the recessing, nestling and cementing ecomorphs displayed much greater asymmetry in shell shape (inequivalved). This pattern may thus be interpreted as a reflection of the way in which the different ecomorphs locomote, as species displaying a more active lifestyle (e.g., gliding) must have a higher degree of symmetry between the right and left valves to reduce hydrodynamic drag (e.g., [43, 84]).

With respect to the pace of evolutionary change, the tempo of the three shell traits (shell asymmetry, left and right valve shape) along the branches of the phylogeny all present a similar pattern among ecomorphs: rates are high in gliding, recessing and nestling species, while comparatively low for the other ecomorphs. This is particularly conspicuous in the shape of the right valve and thus overall shell asymmetry (Figs. $3 b$ \& 4). The right valve is often in contact with the substrate in bivalve species that are in a non-vertical position and evolves different shapes suited to the life habit. For example, the single nestling species, Pedum spondyloideum, is an obligate commensal, where the scallop settles on and then becomes encased as the living scleractinian corals grows around it [85]. Within this chamber, the right valve becomes immobile, while the left valve can move during adduction of the valves. As a result, the right valve is modified during growth to maximise shell gape by displacing the hinge line and the migration of the byssal notch [86]. Higher rates of asymmetry and shape evolution in nestling species in this study are expected for the same environmental reasons. This agrees with what has been shown in other taxa: great morphological variability in shell shape has been described in similar crevice-dwelling species of pterioid 
bivalves [87], which suggests that the variability is inherent property of this specialised life habit. Thus, our observed high rates of shape change in the right valves of species of these three scallop ecomorphs is predicted to be due to natural selection and their respective natural histories.

AP Møller and A Pomiankowski [88] proposed that estimating the degree of trait fluctuating asymmetry (FA), the small asymmetrical differences due to developmental perturbations, would be a good proxy for estimating the pace of evolutionary change. FA reflects the ability of an individual to cope with stress, and traits under strong directional selection, (thus experiencing elevated rates of phenotypic evolution, Lande 1976) would become more susceptible to the influence of stress. They suggested that phenotypic traits from periods of rapid evolutionary change should display high FA and morphological variability, while traits from periods of slow evolutionary change should display low FA and variability. Do our results from scallops support this prediction? We did not measure FA here, but we did measure an evolutionary outcome, directional asymmetry (the difference between the left and right valves). The most inequivalve (highly asymmetrical) ecomorph, where the left value is distinctly flattened and the right valve exhibits a great deal of convexity variation across species, is the recessing scallops. A previously reported directional trend in left valve shape [45] appears to coincide with increasing convexity of the right valve and explains the increasing shell asymmetry we observe in this ecomorph. This trend is a consequence of a macroevolutionary transition from an epifaunal to semiinfaunal existence (see [45] for discussion). The recessing scallops showed high variation in asymmetry across species (Fig. 3a), and elevated rates of evolutionary change (Fig. 4), thus supporting the hypothesis of AP Møller and A Pomiankowski [88]. At the other end of the asymmetry spectrum are the gliding scallops, the most equivalve ecomorph, because the highlysymmetrical left and right valves jointly function as an airfoil during the swimming behaviour [84]. The high rates of shape evolution of both valves, but particularly the left, in all gliding species is probably associated with natural selection for a convergent gliding morphology (discussed in [43]). However, this ecomorph displayed lower variation in asymmetry across species (Fig. 3a), and thus the hypothesis of AP Møller and A Pomiankowski [88] is not supported in this instance. The tendency for scallop shells to evolve back and forth along the asymmetry spectrum, displaying varying degrees of directional asymmetry, while retaining strongly integrated valves, is clearly an important facet of phenotypic evolution in this clade that deserves further investigation.
Finally, placing our results here in the context of a growing body of macroevolutionary work on scallops [43-46] provides several general insights. First, the neutral model of phenotypic evolution provides a framework for the understanding of rates of morphological evolution: unexpectedly low rates result from stabilising selection (e.g., [36]), while high rates of evolution imply natural selection including directional evolution [89]. Scallop macroevolution appears to meet these expectations: there is a baseline low rate of change in shell asymmetry and valve shape among species of the byssal-attaching and free-living ecomorphs (the ancestrally-reconstructed ecomorph state for scallops; [44]), and only along the branches towards the gliding, recessing and nestling species do we see a marked increase in rates. Second, gliding, recessing and cementing ecomorphs have evolved independently multiple times $[44,46]$ and with morphologically similar outcomes (valve shape and shell asymmetry), supporting the predictability of evolution (e.g., [90, 91]). Finally, the evolution of directional asymmetry in scallop shells is shown here to be a fundamental component of scallop macroevolution and is offered as a novel system in which to study the concept of adaptive asymmetry, where fluctuating asymmetry between left and right paired structures provides a selective advantage and becomes directional asymmetry at a macroevolutionary scale [92].

\section{Conclusions}

Our study on scallops adds another strong piece of evidence that ecological shifts play an important role in the tempo and mode of morphological evolution. The results presented here suggest that strong selective pressures from the environment, inferred from the repeated evolution of distinct ecomorphs, have influenced the rate of morphological evolution in scallop valve shape and the magnitude of asymmetry between left and right valves. We observed strong morphological integration between the two valves comprising the shell, and this is consistent across all ecomorphs, which suggests there are distinct, evolutionarily conserved developmental pathways responsible for the concerted evolution of these structures even though environmental pressures are driving whole shell shape. In conclusion, an interplay and morphological integration and directional asymmetry in shell shape among species have played an important role in scallop macroevolution.

\section{Additional file}

Additional file 1: Figure S1. Variation in matching asymmetry in scallop shells across the 86 species, colored by life habit. Table S1. Morphometric data of left and right valves were available for 86 species comprising six life habits. Table S2. Significance ( $P$-values) for pairwise comparisons of effect sizes, Z scores, from partial least squares analysis. (DOCX 220 kb) 


\section{Abbreviations}

DA: Directional asymmetry; FA: Fluctuating asymmetry; PLS: Two-block partial least squares

\section{Acknowledgements}

We are very grateful for the assistance and loans provided by the staff of museums and research institutions, especially J. McLean and L. Groves [LACM]; G. Paulay and J. Slapcinsky [FLMNH]; E. Shea, N. Aziz and L. Skibinski [DMNH]; S. Morrison and C. Whisson [WAM]; E. Strong, T. Nickens, P. Greenhall and T. Walter [NMNH]; E. Lazo-Wasem [YMP]; G.T. Watters [OSUM]; P. Bouchet and P. Maestrati [MNHM]; A. Baldinger [MCZ]; M. Siddall and S. Lodhi [AMNH]; R. Bieler and J. Gerber [FMNH]; R. Kawamoto [BPBM]; E. Kools [CAS]; and A. Bogan and J. Smith [NCSM]. Organization and collection of molecular and morphological data were aided by the team of undergraduate researchers: K. Boyer, D. Brady, K. Cain, G. Camacho, N. Dimenstein, C. Figueroa, A. Flander, A. Frakes, C. Grula, M. Hansel, M. Harmon, S. Hofmann, J. Kissner, N. Laurito, N. Lindsey, S. Luchtel, C. Michael, V. Molian, A. Oake, J. Rivera, H. Sanders, M. Steffen and C. Wasendorf.

\section{Funding}

Financial support was provided by the United States National Science Foundation [DEB-1118884 to JMS and DCA, and DEB-1257287 to DCA] and The University of Adelaide Research Fellowship to ES. The funding bodies did not play a role in the design of the study and collection, analysis, and interpretation of data and in writing the manuscript.

\section{Availability of data and materials}

The datasets generated and analysed during the current study and the R code are available in the DRYAD repository: https://doi.org/10.5061/ dryad.j4n09.

\section{Authors' contributions}

ES, JMS and DCA conceived and designed the experiment, and collected the data. ES and DCA analysed the data. ES wrote the manuscript with input from JMS and DCA. All authors read and approved the final manuscript.

\section{Ethics approval and consent to participate} Not applicable.

\section{Consent for publication}

Not applicable.

\section{Competing interests}

The authors declare that they have no competing interests.

\section{Publisher's Note}

Springer Nature remains neutral with regard to jurisdictional claims in published maps and institutional affiliations.

\section{Author details}

'Department of Genetics and Evolution, School of Biological Sciences, The University of Adelaide, Adelaide, South Australia 5005, Australia. ${ }^{2}$ Department of Ecology, Evolution, and Organismal Biology, lowa State University, Ames, IA 50011, USA. ${ }^{3}$ Department of Statistics, lowa State University, Ames, IA 50011, USA.

Received: 3 August 2017 Accepted: 27 November 2017

Published online: 08 December 2017

\section{References}

1. Lynch $\mathrm{M}$. The rate of morphological evolution in mammals from the standpoint of the neutral expectation. Am Nat. 1990;136(6):727-41.

2. Stanley SM. Rates of evolution. Paleobiology. 1985;11(1):13-26.

3. Gingerich PD. Rates of evolution. Annu Rev Ecol Evol Syst. 2009;40:657-75.

4. Simpson GG. The major features of evolution. New York: Columbia University Press; 1953.

5. Harmon LJ, Schulte JA, Larson A, Losos JB. Tempo and mode of evolutionary radiation in iguanian lizards. Science. 2003;301(5635):961-4.

6. Thomas GH, Freckleton RP, Székely T. Comparative analyses of the influence of developmental mode on phenotypic diversification rates in shorebirds. Proc R Soc B. 2006;273(1594):1619.
7. Lloyd GT, Wang SC, Brusatte SL. Identifying heterogeneity in rates of morphological evolution: discrete character change in the evolution of lungfish (Sarcopterygii; Dipnoi). Evolution. 2012;66(2):330-48.

8. Revell $L$, Collar DC. Phylogenetic analysis of the evolutionary correlation using likelihood. Evolution. 2009;63(4):1090-100.

9. O'Meara BC, Ane C, Sanderson MJ, Wainwright PC. Testing for different rates of continuous trait evolution using likelihood. Evolution. 2006;60(5):922-33.

10. Revell $\sqcup$, Peres-Neto PR, Redelings BD. A new phylogenetic method for identifying exceptional phenotypic diversification. Evolution. 2011;66(1):135-46.

11. Adams DC. Quantifying and comparing phylogenetic evolutionary rates for shape and other high-dimensional phenotypic data. Syst Biol. 2014;63(2):166-77.

12. Adams DC. Comparing evolutionary rates for different phenotypic traits on a phylogeny using likelihood. Syst Biol. 2013;62(2):181-92.

13. Denton JSS, Adams DC. A new phylogenetic test for comparing multiple high-dimensional evolutionary rates suggests interplay of evolutionary rates and modularity in lanternfishes (Myctophiformes; Myctophidae). Evolution. 2015:69(9):2425-40.

14. Eastman JM, Alfaro ME, Joyce P, Hipp AL, Harmon LJ. A novel comparative method for identifying shifts in the rate of character evolution on trees. Evolution. 2011;65(12):3578-89.

15. Rabosky DL, Adams DC: Rates of morphological evolution are correlated with species richness in salamanders. Evolution 2012:In press.

16. Ricklefs RE. Cladogenesis and morphological diversification in passerine birds. Nature. 2004;430(6997):338-41.

17. Harmon L, Losos JB, Davies TJ, Gillespie RG, Gittleman JL, Jennings WB, Kozak $\mathrm{KH}$, Schluter D, Schulte JA II, Seehausen O, et al. Early bursts of body size and shape evolution are rare in comparative data. Evolution. 2010;64:2385-96.

18. Adams DC, Berns CM, Kozak KH, Wiens JJ. Are rates of species diversification correlated with rates of morphological evolution? Proc R Soc B 2009:276(1668):2729-38

19. Derryberry EP, Claramunt S, Derryberry G, Chesser RT, Cracraft J, Aleixo A, Pérez-Emán J, Remsen JJV, Brumfield RT. Lineage diversification and morphological evolution in a large-scale continental radiation: the neotropical ovenbirds and woodcreepers (Aves: Furnariidae). Evolution. 2011;65(10):2973-86

20. Price SA, Holzman R, Near TJ, Wainwright PC. Coral reefs promote the evolution of morphological diversity and ecological novelty in labrid fishes. Ecol Lett. 2011;14(5):462-9.

21. Reynolds RG, Collar DC, Pasachnik SA, Niemiller ML, Puente-Rolón AR, Revell L. Ecological specialization and morphological diversification in greater Antillean boas. Evolution. 2016;70(8):1882-95.

22. Collar DC, Schulte JA, O'Meara BC, Losos JB. Habitat use affects morphological diversification in dragon lizards. J Evol Biol. 2010;23(5):1033-49.

23. Price SA, Tavera JJ, Near TJ, Wainwright PC. Elevated rates of morphological and functional diversification in reef-dwelling haemulid fishes. Evolution. 2012;67(2):417-28

24. Higham TE, Birn-Jeffery AV, Collins CE, Hulsey CD, Russell AP. Adaptive simplification and the evolution of gecko locomotion: morphological and biomechanical consequences of losing adhesion. Proc Natl Acad Sci U S A. 2015;112(3):809-14.

25. Mahler DL, Revell LJ, Glor RE, Losos JB. Ecological opportunity and the rate of morphological evolution in the diversification of greater Antillean anoles. Evolution. 2010:64(9):2731-45.

26. Harmon LJ, Melville J, Larson A, Losos JB. The role of geography and ecological opportunity in the diversification of day geckos (Phelsuma). Syst Biol. 2008;57(4):562-73.

27. Burbrink F, Pyron R. How does ecological opportunity influence rates of speciation, extinction, and morphological diversification in new world ratsnakes (tribe Lampropeltini)? Evolution. 2010;64(4):934-43.

28. Ramírez-Barahona S, Barrera-Redondo J, Eguiarte LE. Rates of ecological divergence and body size evolution are correlated with species diversification in scaly tree ferns. Proc Biol Sci. 2016;283(1834). doi:10.1098/ rspb.2016.1098.

29. Salvidio S, Crovetto F, Adams DC. Potential rapid evolution of foot morphology in Italian plethodontid salamanders (Hydromantes strinatii) following thecolonization of an artificial cave. J Evol Biol. 2015;28(7):1403-9.

30. Hendry AP, Farrugia TJ, Kinnison MT. Human influences on rates of phenotypic change in wild animal populations. Mol Ecol. 2008;17(1):20-9.

31. Reznick DN, Shaw FH, Rodd FH, Shaw RG. Evaluation of the rate of evolution in natural populations of guppies (Poecilia reticulata). Science. 1997;275(5308):1934-7. 
32. Klaczko J, Ingram T, Losos J. Genitals evolve faster than other traits in Anolis lizards. J Zool. 2015;295(1):44-8

33. Linde-Medina M, Boughner JC, Santana SE, Diogo R. Are more diverse parts of the mammalian skull more labile? Ecol Evol. 2016;6(8):2318-24.

34. Kaliontzopoulou A, Carretero MA, Adams DC. Ecomorphological variation in male and female wall lizards and the macroevolution of sexual dimorphism in relation to habitat use. J Evol Biol. 2015;28(1):80-94.

35. Wheatcroft $D$, Price TD. Rates of signal evolution are associated with the nature of interspecific communication. Behav Ecol. 2015;26(1):83-90.

36. Adams DC, Korneisel D, Young M, Nistri A. Natural history constrains the macroevolution of foot morphology in European plethodontid salamanders. Am Nat. 2017;190(2):292-7.

37. Tsuboi M, Gonzalez-Voyer A, Kolm N. Functional coupling constrains craniofacial diversification in Lake Tanganyika cichlids. Biol Lett. 2015;11(5): 20141053.

38. Klingenberg CP. Integration, modules and development: molecules to morphology to evolution. In: Pigliucci M, Preston K, editors. Phenotypic integration: studying the ecology and evolution of complex phenotypes. New York: Oxford University Press; 2004. p. 213-30.

39. Melo D, Marroig G. Directional selection can drive the evolution of modularity in complex traits. Proc Natl Acad Sci U S A. 2015;112(2):470-5.

40. Garland K, Marcy A, Sherratt E, Weisbecker V. Out on a limb: bandicoot limb co-variation suggests complex impacts of development and adaptation on marsupial forelimb evolution. Evol Dev. 2017;19(2):69-84.

41. Martín-Serra A, Figueirido B, Perez-Claros JA, Palmqvist P. Patterns of morphological integration in the appendicular skeleton of mammalian carnivores. Evolution. 2015;69(2):321-40.

42. Frédérich B, Olivier D, Litsios G, Alfaro ME, Parmentier E. Trait decoupling promotes evolutionary diversification of the trophic and acoustic system of damselfishes. Proc R Soc B. 2014;281(1789):20141047. doi:10.1098/rspb.2014. 1047.

43. Serb JM, Sherratt E, Alejandrino A, Adams DC. Phylogenetic convergence and multiple shell shape optima for gliding scallops (Bivalvia: Pectinidae). J Evol Biol. 2017;30(9):1736-47.

44. Alejandrino A, Puslednik L, Serb JM. Convergent and parallel evolution in life habit of the scallops (Bivalvia: Pectinidae). BMC Evol Biol. 2011;11(1):164.

45. Sherratt E, Alejandrino A, Kraemer AC, Serb JM, Adams DC. Trends in the sand: directional evolution in the shell shape of recessing scallops (Bivalvia: Pectinidae). Evolution. 2016;70(9):2061-73.

46. Serb JM, Alejandrino A, Otárola-Castillo E, Adams DC. Morphological convergence of shell shape in distantly related scallop species (Mollusca: Pectinidae). Zool J Linnean Soc. 2011;163(2):571-84.

47. Stanley SM. Relation of shell form to life habits of the Bivalvia (Mollusca). Geological Soc Am Mem. 1970;125:1-296.

48. Serb JM. Reconciling morphological and molecular approaches to develop a phylogeny for the Pectinidae (Mollusca: Bivalvia). In: Shumway S, Parsons GJ, editors. Scallops: Biology, Ecology and Aquaculture, vol. 40, 3rd edn. Elsevier Science; 2016. p. 1-28.

49. Savriama Y, Klingenberg CP. Beyond bilateral symmetry: geometric morphometric methods for any type of symmetry. BMC Evol Biol. 2011;11(1):280.

50. Savazzi E. The function and evolution of lateral asymmetry in boring endolithic bivalves. Paleontol Res. 2005;9:169-87.

51. Verrill. A study of the family Pectinidae, with a revision of general and subgenera. Trans Conn Acad Arts Sci. 1897;10:41-95.

52. Waller TR. The Pectinidae (Mollusca: Bivalvia) of Eniwetok atoll, Marshall Islands. The Veliger. 1972;14:221-64.

53. Klingenberg CP, Mclntyre GS. Geometric morphometrics of developmental instability: analyzing patterns of fluctuating asymmetry with procrustes methods. Evolution. 1998;52(5):1363-75.

54. Klingenberg CP, Mclntyre GS, Zaklan SD. Left-right asymmetry of fly wings and the evolution of body axes. Proc R Soc B. 1998;265(1402):1255-9.

55. Carter JG, Harries PJ, Malchus N, Sartori AF, Anderson LC, Bieler R, Bogan AE, Coan EV, Cope JCW, Cragg S, et al. Illustrated glossary of the bivalvia. Treatise Online. 2012;48:1-209.

56. Adams DC, Felice R. Assessing phylogenetic morphological integration and trait covariation in morphometric data using evolutionary covariance matrices. PLoS One. 2014;9(4):e94335.

57. Bookstein FL. Morphometric tools for landmark data: geometry and biology. New York: Cambridge Univ. Press; 1991.

58. Mitteroecker P, Gunz P. Advances in geometric morphometrics. Evol Biol. 2009;36(2):235-47.
59. Adams DC, Rohlf FJ, Slice DE. A field comes of age: geometric morphometrics in the 21st century. Hystrix. 2013;24:7-14.

60. Gunz P, Mitterocker P, Bookstein FL. Semilandmarks in three dimensions. In: Slice DE, editor. Modern morphometrics in physical anthropology. New York: Kluwer Academic/Plenum Publishers; 2005. p. 73-98.

61. Waller TR. The evolution of the Argopecten gibbus stock (Mollusca: Bivalvia), with emphasis on the tertiary and quaternary species of eastern North America. Memoir (The Paleontological Society). 1969;3:i-125.

62. Rohlf FJ, Slice D. Extensions of the Procrustes method for the optimal superimposition of landmarks. Syst Zool. 1990;39(1):40-59.

63. R Core Team (2017). R: A language and environment for statistical computing. Vienna: R Foundation for Statistical Computing. http://www.Rproject.org/.

64. Adams DC, Collyer ML, Kaliontzopoulou A, Sherratt A. Geomorph: software for geometric morphometric analyses. R package version 3.0.4. 2017. https:// cran.r-project.org/package=geomorph.

65. Rohlf FJ, Corti M. Use of two-block partial least-squares to study covariation in shape. Syst Biol. 2000;49(4):740-53.

66. Adams DC, Collyer ML. On the comparison of the strength of morphological integration across morphometric datasets. Evolution. 2016;70(11):2623-31.

67. Klingenberg CP. Visualizations in geometric morphometrics: how to read and how to make graphs showing shape changes. Hystrix. 2013;24(1):15-24.

68. Sherratt E, Gower DJ, Klingenberg CP, Wilkinson M. Evolution of cranial shape in caecilians (Amphibia: Gymnophiona). Evol Biol. 2014;41:528-45.

69. Adams DC. A method for assessing phylogenetic least squares models for shape and other high-dimensional multivariate data. Evolution. 2014;68:2675-88.

70. Revell LJ. Phytools: an R package for phylogenetic comparative biology (and other things). Methods Ecol Evol. 2012;3(2):217-23.

71. Paradis E, Claude J, Strimmer K. Ape: analyses of Phylogenetics and evolution in R language. Bioinformatics. 2004;20(2):289-90.

72. Raup DM. Geometric analysis of shell coiling: general problems. J Paleontol. 1966;40:1178-90.

73. Savazzi E. Geometric and functional constraints on bivalve shell morphology. Lethaia. 1987;20:293-306.

74. Ubukata T. Theoretical morphology of hinge and shell form in Bivalvia: geometric constraints derived from space conflict between umbones. Paleobiology. 2000;26(4):606-24.

75. Von Dassow G, Munro E. Modularity in animal development and evolution: elements of a conceptual framework for EvoDevo. J Exp Zool Part B Mol Dev Evol. 1999;285(4):307-25

76. Wagner G, Altenberg L. Complex adaptations and the evolution of evolvability. Evolution. 1996;50(3):967-76.

77. Eble GJ. The macroevolution of phenotypic integration. In: Pigliucci M, Preston K, editors. Phenotypic integration: studying the ecology and evolution of complex phenotypes. Oxford: Oxford University Press; 2004. p. 253-73.

78. Kocot KM, Cannon JT, Todt C, Citarella MR, Kohn AB, Meyer A, Santos SR, Schander C, Moroz LL, Lieb B, et al. Phylogenomics reveals deep molluscan relationships. Nature. 2011;477(7365):452-6.

79. Smith SA, Wilson NG, Goetz FE, Feehery C, Andrade SC, Rouse GW, Giribet $\mathrm{G}$, Dunn CW. Resolving the evolutionary relationships of molluscs with phylogenomic tools. Nature. 2011;480(7377):364.

80. Yonge CM. The monomyarian condition in the Lamellibranchia. Trans R Soc Edinb. 1953;62(2):443-78.

81. Jacobs DK, Wray CG, Wedeen CJ, Kostriken R, DeSalle R, Staton JL, Gates RD, Lindberg DR. Molluscan engrailed expression, serial organization, and shell evolution. Evol Dev. 2000;2:340-7.

82. Anderson PSL, Smith DC, Patek SN. Competing influences on morphological modularity in biomechanical systems: a case study in mantis shrimp. Evol Dev. 2016;18(3):171-81.

83. Claverie T, Patek SN. Modularity and rates of evolutionary change in a power-amplified prey capture system. Evolution. 2013;67(11):3191-207.

84. Hayami I. Living and fossil scallop shells as airfoils: an experimental study. Paleobiology. 1991;17(1):1-18.

85. Yonge CM. Observations on Pedum spondyloideum (Chemnitz) Gmelin, a scallop associated with reef-building corals. Proc Malacologial Soc Lond. 1967:37:311-23.

86. Savazzi E. Constructional morphology of the bivalve Pedum. In: Johnston PA, Haggart JW, editors. Bivalves: an eon of evolution. Calgary: University of Calgary Press; 1998. p. 413-22. 
87. Ubukata T. A morphometric study on morphological plasticity of shell form in crevice-dwelling Pterioida (Bivalvia). Biol J Linn Soc. 2003;79(2):285-97.

88. Møller AP, Pomiankowski A. Punctuated equilibria or gradual evolution: fluctuating asymmetry and variation in the rate of evolution. J Theor Biol. 1993;161(3):359-67.

89. Lande R. Natural selection and random genetic drift in phenotypic evolution. Evolution. 1976;30(2):314-34.

90. Losos JB. Convergence, adaptation, and constraint. Evolution. 2011;65(7):1827-40.

91. Vermeij GJ. Historical contingency and the purported uniqueness of evolutionary innovations. Proc Natl Acad Sci U S A. 2006;103(6):1804-9.

92. Møller AP, Swaddle JP. Asymmetry, developmental stability and evolution. UK: Oxford University Press; 1997.

Submit your next manuscript to BioMed Central and we will help you at every step:

- We accept pre-submission inquiries

- Our selector tool helps you to find the most relevant journal

- We provide round the clock customer support

- Convenient online submission

- Thorough peer review

- Inclusion in PubMed and all major indexing services

- Maximum visibility for your research

Submit your manuscript at www.biomedcentral.com/submit
Biomed Central 